\title{
A Study on the Impact of Urban River Refurbishment to the Thermal Environment of Surrounding Residential Area
}

\author{
Daewuk Kim, Jae-Gyu Cha, Eung-Ho Jung \\ Department of Environmental Planning, Keimyung University, Daegu, South Korea \\ Email: dwkim@kmu.ac.kr, top4mir@gmail.com, turep21@kmu.ac.kr
}

Received 4 March 2014; revised 2 April 2014; accepted 19 April 2014

Copyright (C) 2014 by authors and Scientific Research Publishing Inc.

This work is licensed under the Creative Commons Attribution International License (CC BY). http://creativecommons.org/licenses/by/4.0/

(c) (i) Open Access

\begin{abstract}
In this study, a simulation was conducted targeting Beomeo stream of Daegu, for the purpose of the quantitative determination of the changes in thermal environment of surrounding residential areas according to the urban river refurbishment. For the study method, the reviews of literature and model verification were conducted, and then the results were derived through the process of comparing and analyzing the thermal environment resulting from the river refurbishment of the target area. As a result of the model verification, the accuracy of modeling was $95 \%$. As a result of a simulation of the target area, in respect of the fluctuation of temperature, the temperature decreased by $1.33^{\circ} \mathrm{C}$ more in the daytime than in the night time, due to the river refurbishment. In respect of the positions, the decrease of the temperature was $1.33^{\circ} \mathrm{C}$ at $2 \mathrm{pm}$ at position 1 , the position of river refurbishment, and the highest in the entire time slots. Also, the changes in temperature increasingly decreased from position 1 to position 4 . It seemed that it was because there was the highest radiant heat at position 1 with the biggest gap between artificial mulching and natural mulching, and the effect of the gap in the radiant heat influenced successively over position 2,3 and 4. Lastly, in respect of the effect of river refurbishment on the surrounding area, the effect reached to position 3 , in other word, 60 meters from the river.
\end{abstract}

\section{Keywords}

Residential Area, Urban Heat Island, Urban Micro Climate, River Refurbishment, Thermal Environment

\section{Introduction}

The benefits derived from rivers do not just include flood control and water utilization, they also provide places

How to cite this paper: Kim, D., et al. (2014) A Study on the Impact of Urban River Refurbishment to the Thermal Environment of Surrounding Residential Area. Journal of Environmental Protection, 5, 454-465.

http://dx.doi.org/10.4236/jep.2014.55048 
for relaxation and improve ecological functions. Also, rivers greatly contribute to urban heat island mitigation by creating various waterfront areas [1]. However, because of urbanization and industrialization, massive housing complexes, roads and commercial complexes have been built. Therefore, rivers in urban areas have been covered with concrete and asphalt, losing their functions as rivers. As the economy has developed, so has the desire of people for a better life and more pleasing natural surroundings. Therefore, the government has adopted nature-friendly river improvement techniques to enhance the natural environment and schemas have been established for river areas. In particular, the government established the 4 major rivers refurbishment project and local governments have also established local river improvement \& refurbishment plans. Daegu metropolitan city is conducting the Beomeo stream improvement plan as a part of efforts to preserve local rivers. The Cheonggye stream project is a representative case of a successful river improvement project, and after the refurbishment construction was completed it was praised for not only enhancing social economic conditions around Chenggye stream but also for mitigating the heat island phenomenon and for generally improving the environment [2] [3].

Therefore, in this research, we have conducted onsite measurements and simulations for Beomeo stream, which is the representative river project of river restoration of Daegu city, in order to increase reliability of modeling simulations, and the objective of this research was to find out the level of temperature reduction quantitatively by comparing and analyzing the temperature reduction effect in residential areas around the river before and after the river refurbishment.

The time scope of this research is limited to the summer season when discomfort caused by the heat island phenomenon is expected, and the area focused on is Beomeo stream. With regard to the scope of content, it is limited to the micro climate environment which has a close relationship with the residential environment, and the analysis is limited to the thermal environment in relation to the river refurbishment, especially the influence of temperature change on the area around the river.

This research conducted onsite measurements and compared simulation results in order to verify the reliability of modeling simulations, and then simulations were carried out with regard to thermal environmental changes before and after the river refurbishment, and finally we compared and analyzed the results of simulations. First of all, in the literature review, we looked at the concept behind micro climate and thermal environment, along with the functions and roles of urban rivers in order to reestablish the concepts and understand research trends. In the basic research conducted to establish the target area's characteristics and surrounding conditions, we constructed a database that included details such as the height of buildings in the target area and the residential area around the river, plants, land coverage status, digital maps and aerial photographs, and Landsat imagery. Also, we utilized the automatic weather eye (Vantage VUE) for the target area, in order to carry out onsite measurements of the microclimate environment in the target area and the area around it. The onsite measurements were taken in the area where the river is being constructed presently, and with the automatic weather eye (Vantage VUE) the micro climate environment (temperature and wind) was measured at $30 \mathrm{~m}$ intervals from the river to the residential commercial area. Based on the values we obtained onsite, the ENVI-Met (Beta II V3.1), which is a 3D micro climate model and was used from many other articles for the simulation of urban micro climate [4]-[6], was utilized to carry out micro climate environment simulations in order to increase the reliability of modeling for the simulations. Finally, we compared and analyzed the influence of temperature reduction caused by the river refurbishment in the residential area around the river before and after the river refurbishment, by carrying out a simulation on the covering section in the target area. To summarize the research method and process, refer to Figure 1.

\section{River Refurbishment \& Micro Climate}

The term "river" includes running streams that form ecological relationships with people and benefit them, and the term also includes river sections of the water system and river adjuncts as well [7]. The primary functions of a river are water regulation and flood control. In the 20th century, the population in Korea increased and secondary and tertiary industries were developed more than primary industries. During this stage, people became more aware of environmental functions. Environmental functions include habitation for animals and plants around the river, self-purification of water and aesthetics. The aesthetic function can be called a water-friendly function. Recently, this function includes mitigating the urban heat island phenomenon as well as having a connection with the microclimate [8]. There are 5 types of rivers, and they can be classified into natural rivers, disaster prevention rivers, private use rivers, park rivers, and natural form rivers (ecological rivers) in accordance 




Figure 1. Flowchart of this study.

with their different stages of evolution. The natural river is a river that mostly maintains its natural state, and the disaster prevention river is a river that has been refurbished in order to have water regulation and flood control functions. The private use river is a river where the river site is occupied for some other purpose, and the park river is a river that has been refurbished to stress its water-friendly function. Finally the natural form river is a river refurbished primarily as a habitat for organisms, and this is a kind of river refurbished as part of river improvement work that is taking place these days [9]. Beomeo stream is one of these kinds.

The definition of river refurbishment refers to the restoration of the physical shape and ecological function of a river, which has been damaged. In other words, it is to recover the basic functions of a river such as the self-purification function, enhance surrounding scenery and preserve biotic diversity, and to restore the waterway and waterfront to its original natural river shape [10]. The types of river refurbishment include recovery of original form, recovery to similar form and substitution recovery. The recovery of original form involves restoring the disturbed ecosystem to its original form as much as possible, to restore the original natural conditions and ecological functions. Recovery to a similar form involves stabilizing the disturbed ecosystem to maintain its ecological functions. Finally, substitution recovery involves building an ecosystem artificially to meet its original purpose [11]. Thus, as ecologic river refurbishment restores water regulation and flood control function to rivers, along with mitigating the urban heat island phenomenon, much effort has been put into this kind of work at the national and local government level. The river refurbishment work by year in our country is given in the Figure 2 [12]. 


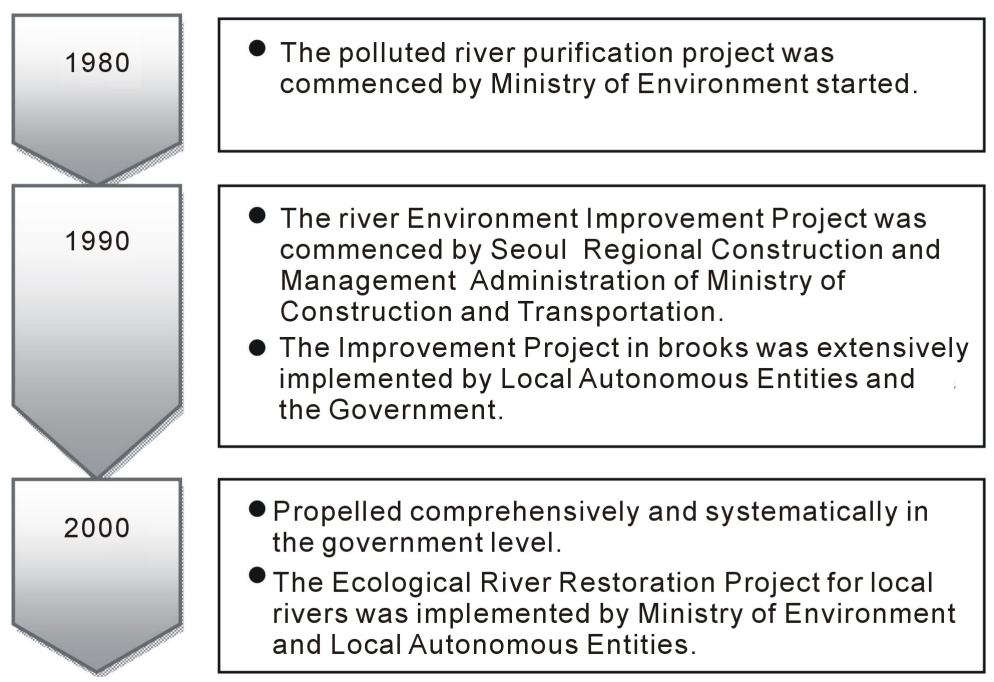

Figure 2. Stream-restoration plan in Korea.

\section{Case Study}

\subsection{Study Area}

1) Background of study area selection

The refurbishment of a river in a city can change the land surface that comprises asphalt into waters. The greens and waters built in the city form low temperature zones in the urban area, where there is a lot of artificial heat emission [13]. It will have a direct effect on reducing the urban heat island phenomenon, and it also enhance the living environment by increasing wind speed by decreasing the earth surface friction speed [14]. Because of this, in 2009 the Ministry of Environment selected 10 areas of local rivers (1st phase work) as a part of the "Cheonggye stream +20 project" which is a refurbishment project for 20 dry rivers and covered rivers that have lost their function as rivers because of ecosystem damage, drying up of streams and water quality deterioration. Beomeo stream is the only target area of river refurbishment work in Daegu city among the selected rivers [11].

Therefore in this research, the representative river of Daegu city—Beomeo stream—has been selected as the target area of this case study.

2) Current status of the study area

Beomeo stream in Daegu city is the first branch of Sincheon that is located in the southeastern part of the south in our country, and it flows from approximately the $4.8 \mathrm{~km}$ upper side of the river mouth of Sincheon to the right bank of Sincheon. The river valley is located between longitude $128^{\circ} 37^{\prime}-128^{\circ} 43^{\prime}$ and latitude $35^{\circ} 47^{\prime}$ $35^{\circ} 52^{\prime}$. In the north, its boundary is between Jung-Gu and Nam-Gu of Daegu metropolitan city, and closed to the river valley of Sincheon. In the east, it is closed to Iceon-Dong and Manchon-Dong in Daegu metropolitan city. The river valley area of Beomeo stream is $27.3 \mathrm{~km}^{2}$, and it has a stream length of $12.0 \mathrm{~km}$. It originates from mountain Byeongpoong in Beommul-Dong, Soosung-Gu, flows down to the northwest, and then goes through the median strip in Dongdaegu-ro right at the $4.9 \mathrm{~km}$ point, and then leaves Dongdaegu-ro at the site of a children's center. It goes through the city in a northwest direction, and then flows in to Sincheon, which is a local river, on the upper right bank side from Dongshingyo [12]. However, Beomeo stream has become a covered section except for the $0.7 \mathrm{~km}$ section from the upper side of Dongshingyo (where it flows from the children's center to the northwest), and only the Hwanggeum crossroad—at the children's center—remains as a river section (Refer to the Figure 3).

Currently, Beomeo stream is located at the center of Daegu metropolitan city along with Sincheon, and the areas around Beomeo stream are mostly concentrated with commercial areas and residential areas. The floating population is big and the traffic heavy, making the street always seems busy.

\subsection{Modeling Verification for the Stream Section}

1) Stream section onsite measurement 




Figure 3. Location of study area.

The thermal environment of the stream section in the study area has been measured in order to obtain basic values for future simulation, and onsite measurement has been conducted for the stream section in order to increase the reliability of the modeling simulation after comparing and analyzing the simulation value with the value obtained from the onsite measurement. The target area of the stream section has been selected to be the section from TBC Daegu broadcasting to Daewoo Trump World Soosung Apartment, the section area is approximately $89,720 \mathrm{~m}^{2}$ and the length of the stream is approximately $340 \mathrm{~m}$. The area around the stream consists of a general residential area and commercial area, and there are 8 lane highways on both sides of the stream. There are street trees planted at the edge of the sidewalk. The ground surface status is mainly covered with concrete, except for the highway (asphalt) and sidewalk (precast block). The measurement point of the stream section and the measurement picture are shown in Figure 4, and for the measurement method, 4 automatic weather eyes (Vantage Vue) were used from the 10 p.m. on 30th August 2011 to 10 p.m. on the 31st of August 2011 in 1 minute intervals for 24 hours. The measurement point is from TBC Daegu broadcasting to Daewoo Trump World Soosung Apartment, and 4 points at the same 30m distance intervals in the residential area around the stream were measured.

2) Modeling for simulation

The scope of the study area for the simulation and the date of the simulation were set at the same time with the onsite measurement. The Figure 4 is an outline picture of the modeling. As with the onsite measurement, 4 points were selected at $30 \mathrm{~m}$ intervals around the river, and the conditions of the modeling for the simulation are shown in Table 1.

Table 1 is a basic input value of the simulation, and the Envi-met (v 3.1) has been utilized for the simulation program. The time of the simulation was set at the same as the onsite measurement, which was from 10 p.m. on the 31 st of August 2011 for 24 hours. The initial temperature value was $33.2^{\circ} \mathrm{C}$, which was the highest temperature when the onsite measurement was taken. The highest temperature was set as the initial temperature value because we could obtain the ideal result with the highest temperature, after trying different initial values in same condition. And the initial wind speed was set to south, and the wind speed was $2.2 \mathrm{~m} / \mathrm{s}$ which was where the fastest wind speed during the day was recorded when the onsite measurement was taken. As for the wind speed value, we have set the highest value as the initial value as well. The reason for this is the same as for the initial temperature value setting.

3) Modeling verification by onsite measurement result

a) Result of the onsite measurement

The graph for the onsite measurement result for each of the points in the target area is shown in Figure 5 . 

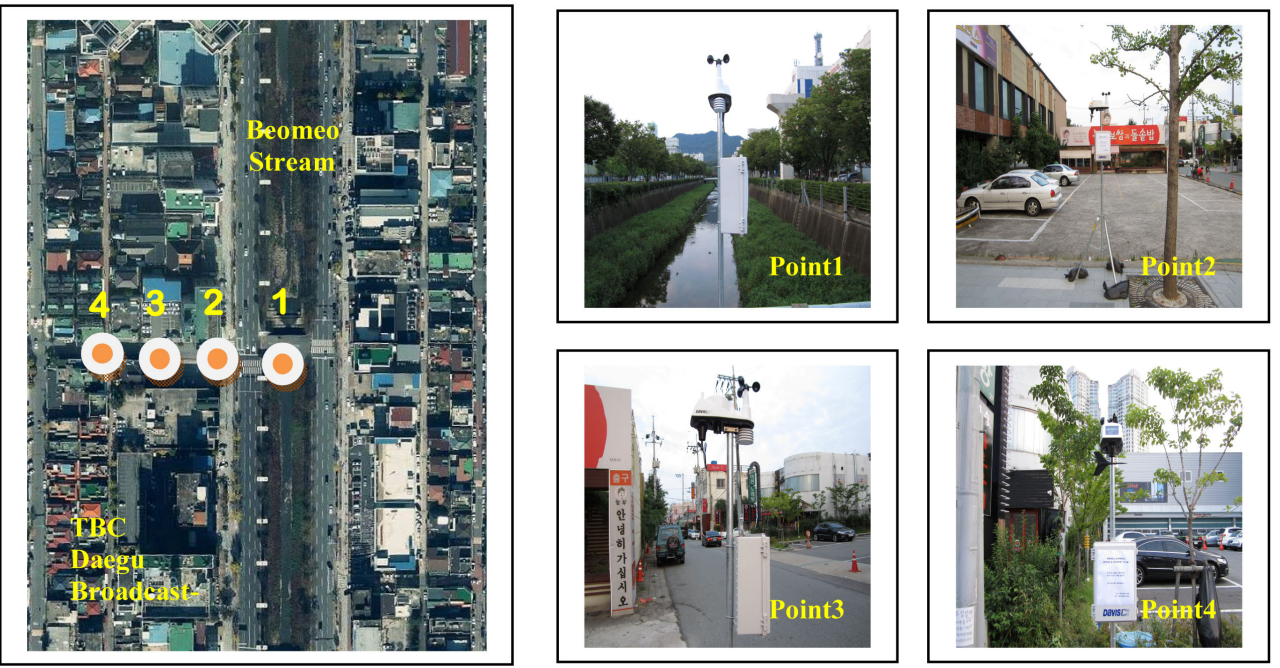

Figure 4. Location pictures for oinsite measurement.

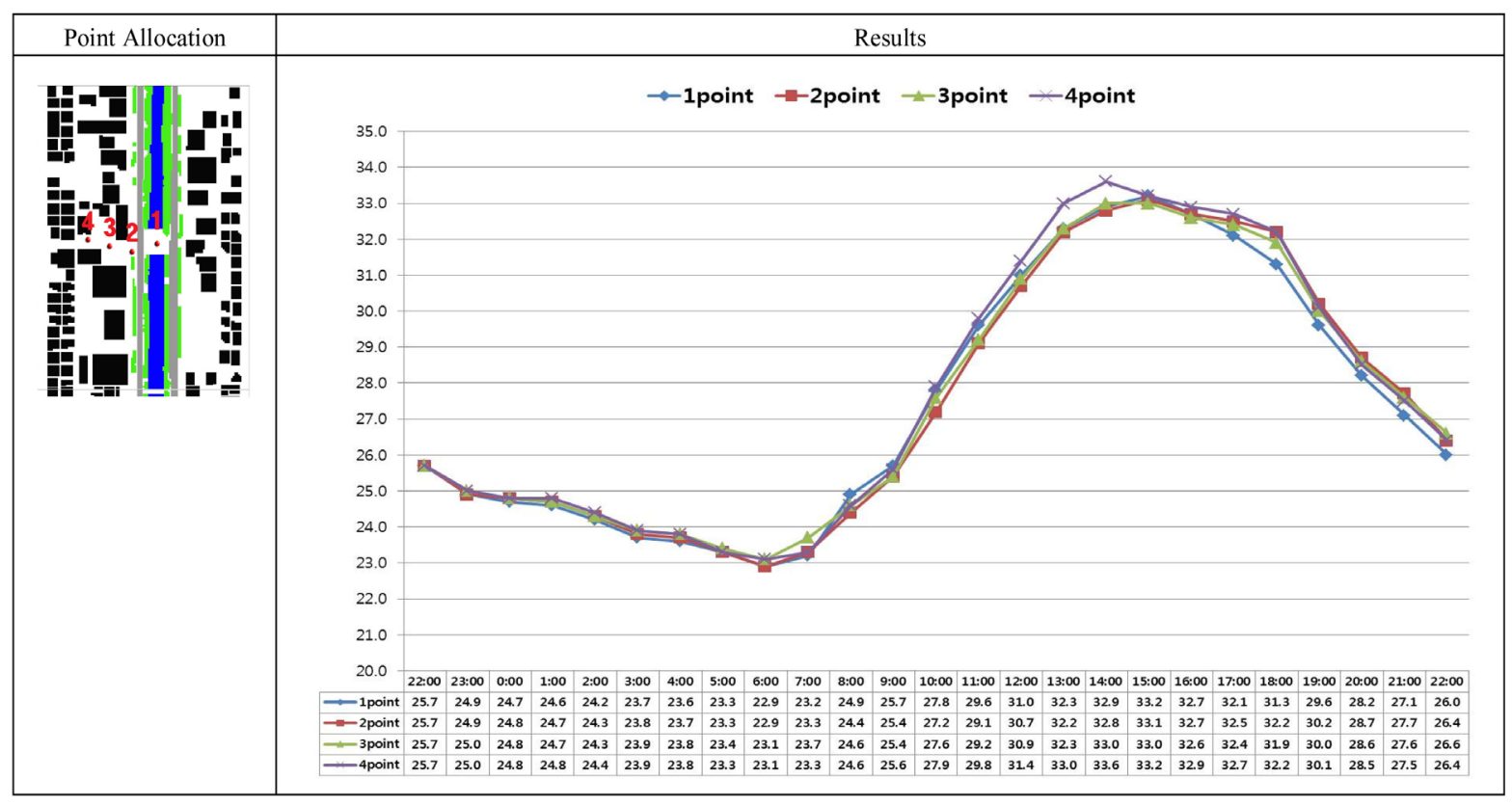

Figure 5. Result-comparison of onsite measurement for each points.

Table 1. Input-value for simulation.

\begin{tabular}{ccccccccc}
\hline Index & Model & $\begin{array}{c}\text { Start } \\
\text { Time }\end{array}$ & Duration & $\begin{array}{c}\text { Saving } \\
\text { Interval }\end{array}$ & $\begin{array}{c}\text { Initial } \\
\text { Temperature }\end{array}$ & $\begin{array}{c}\text { Wind } \\
\text { Direction }\end{array}$ & $\begin{array}{c}\text { Wind } \\
\text { Speed }\end{array}$ & $\begin{array}{c}\text { Relative } \\
\text { Humidity }\end{array}$ \\
\hline $\begin{array}{c}\text { Input } \\
\text { Value }\end{array}$ & $\begin{array}{c}\text { Envi-met } \\
\text { (Ver.3.1) }\end{array}$ & PM 10:00 & 24 Hours & 30 Min. & $33.2^{\circ} \mathrm{C}$ & $\begin{array}{c}\text { South } \\
\left(180^{\circ}\right)\end{array}$ & $2.2 \mathrm{~m} / \mathrm{s}$ & $72.9 \%$ \\
\hline
\end{tabular}

From the point 1 to point 4, the temperature dropped from 10 p.m. on the 30th to 6 a.m. on the 31st, and then the temperature gradually increased from the 7 a.m. on the 31st. The time when the temperature was the highest was from 2 p.m.-3 p.m. on the 31st at every 4 points.

The average temperature value for each point of the onsite measurement was $27.4^{\circ} \mathrm{C}$ at point $1,27.5^{\circ} \mathrm{C}$ at point $2 / 3$ and $27.7^{\circ} \mathrm{C}$ at point 4 . The average temperature value at point 4 was the highest. Comparing point 1 with point 4 , it is revealed that the most significant difference in temperature was $0.7^{\circ} \mathrm{C}$ between 1 p.m. and 2 
p.m. Comparing day time with night time, the temperature difference for each point was higher in the day time than at night time.

b) Simulation result by modeling

The graph of the simulation result for each point in the target area is shown in Figure 6. The temperature dropped gradually from the point 1 to point 4 from $10 \mathrm{p} . \mathrm{m}$. on the 30th to $6 \mathrm{a} . \mathrm{m}$. on the 31st. And then the temperature gradually increased from $7 \mathrm{a} . \mathrm{m}$. on the 31st. This result is the same as the onsite measurement result. The time when the highest temperature occurred at every 4 points was between 2 p.m. and 3 p.m. on the 31st. This was also same with the onsite measurement.

The average temperature value for each point of the simulation was $27.1^{\circ} \mathrm{C}$ at point $1,27.0^{\circ} \mathrm{C}$ at point 2 , $27.5^{\circ} \mathrm{C}$ at point 3 and $27.4^{\circ} \mathrm{C}$ at point 4 . The average temperature value at point 3 was the highest, showing a $0.5^{\circ} \mathrm{C}$ temperature difference compared to point 2 . And if we look at that in time order manner, the temperature difference between point 1 and point 4 at $3 \mathrm{p} . \mathrm{m}$. was $1.6^{\circ} \mathrm{C}$, which is the biggest difference. Comparing day time with night time, the temperature difference for each point was higher in the day time than the night time.

c) Modeling verification by comparing onsite measurement and simulation

The comparison of onsite measurement and simulation for the target area is shown in Table 2. Comparing each of the points, the average temperature in the onsite measurement at the point 1 was $27.4^{\circ} \mathrm{C}$ and the simulation result was $27.1^{\circ} \mathrm{C}$, showing a $0.3^{\circ} \mathrm{C}$ difference. At point 2, the average temperature in the onsite measurement was $27.5^{\circ} \mathrm{C}$ and $27.0^{\circ} \mathrm{C}$ in the simulation, showing a $0.5^{\circ} \mathrm{C}$ difference. At point 3 , the average temperature in both the onsite measurement and simulation was same at $27.5^{\circ} \mathrm{C}$. At point 4 , the average temperature in the onsite measurement was $27.7^{\circ} \mathrm{C}$ and $27.4^{\circ} \mathrm{C}$ in the simulation, showing a $0.3^{\circ} \mathrm{C}$ difference.

If we look at that in time order manner for both onsite measurement and simulation, the temperature dropped from 10 p.m. on the 30th to 7 a.m. on the 31st at each 4 points. And then the temperature increases until 2 p.m. on the 31st. Also, if we look at the detailed comparison results by time for the onsite measurement and the simulation in Table 2, the highest temperature difference was $2.7^{\circ} \mathrm{C}$ at $10 \mathrm{p} . \mathrm{m}$. on the 30th. However, the lowest temperature difference was $0.1^{\circ} \mathrm{C}$ at $7 \mathrm{p} . \mathrm{m}$. As we can see from these results, the accuracy of the modeling verification by onsite measurement and simulation is on average 95\%. Therefore, it is believed that the main experiment of this research — which is the simulation of the temperature reducing effect before/after the river refurbishment—will have an accuracy of 95\%.

Finally, putting together the modeling verification result through the onsite measurement and simulation in a time order manner, the 4 points show a similar temperature increase and decrease distribution. We consider this to enhance the reliability of the target area modeling for the simulation. However, the temperature difference that was recorded between the onsite measurement and the simulation from 10 p.m. on the 30th to 6 a.m. on the 31st at every 4 points is because of various thermal environment variables. Therefore, in order to improve this, a more accurate model should be developed first.

\subsection{Thermal Environment Analysis for the Covered Section}

1) Conditions for analysis

The target area for this simulation was a place with a stream, but now covered with a road. There are two primary input conditions for the implementation of the simulation. First, the configuration files for setting the simulation time, storage interval, and initial microclimate conditions. Second, the area input file for setting the type of ground covering, plants and composition of the buildings. The initial input value of the configuration file is shown in Table 3. And the for the input file setting, landsat imagery provided by Daum was utilized to measure the location of the buildings, plants and roads, and the data input was made after checking the ground covering status through an in-site survey. Also, the models for the simulation before and after the refurbishment are same $-127 \times 175 \times 40$ Grids and the size of each cell is set to $2 \mathrm{~m}$.

In the simulation, an existing road (width $25 \mathrm{M}$ ) was restored to a river. Finally, the river as a center, point 1 , point 2, point 3 and point 4 are selected, each at $30 \mathrm{~m}$ intervals from the river, in order to analyze influence of the river restoration on the area around it (Refer to Figure 7).

2) Thermal environment analysis before/after the river restoration

Figure 8 is a temperature comparison graph for each point in the target area in time order. Except for 2 p.m., the temperature increases more from point 1 to point 4 at 2 a.m., 8 a.m. and 8 p.m.

On the other hand, the temperature decreases more from point 1 to point 4 at $2 \mathrm{p} . \mathrm{m}$. as the solar radiation 


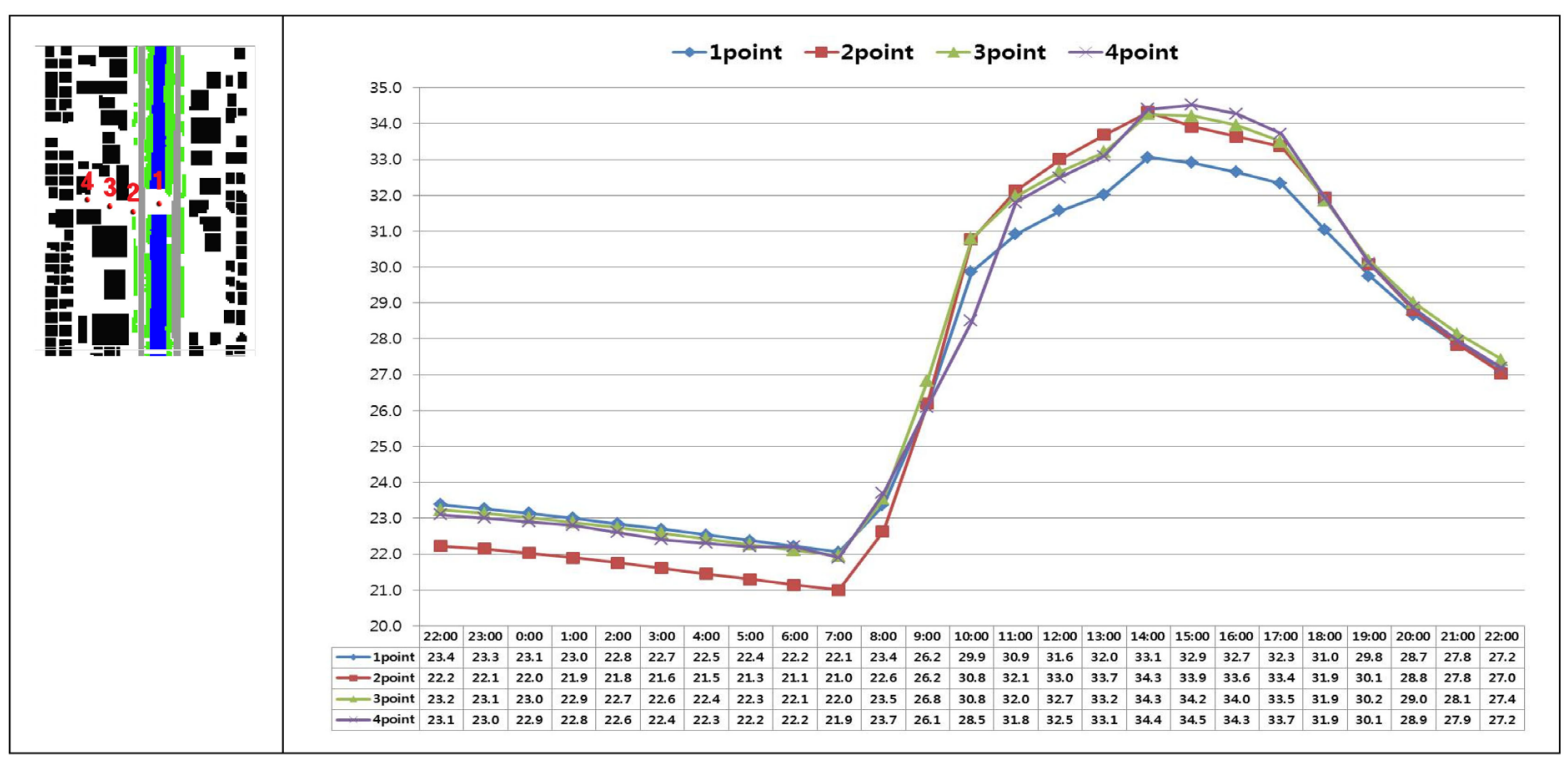

Figure 6. Result-comparison of simulation for each points.

Table 2. Result-comparison between onsite measurement able type styles.

\begin{tabular}{ccccc}
\hline Time & Onsite $\left({ }^{\circ} \mathbf{C}\right)$ & Simulation $\left({ }^{\circ} \mathbf{C}\right)$ & Increment $\left({ }^{\circ} \mathbf{C}\right)$ & Accuracy $(\%)$ \\
\hline $22: 00$ & 25.7 & 23.0 & -2.7 & 89.5 \\
$24: 00$ & 24.8 & 22.8 & -2.0 & 91.9 \\
$02: 00$ & 24.3 & 22.5 & -1.8 & 92.6 \\
$04: 00$ & 23.7 & 22.2 & -1.5 & 93.7 \\
$06: 00$ & 23.0 & 21.9 & -1.1 & 95.2 \\
$08: 00$ & 24.6 & 23.3 & -1.3 & 94.7 \\
$10: 00$ & 27.6 & 30.0 & 2.4 & 92.0 \\
$12: 00$ & 31.0 & 32.4 & 1.4 & 95.7 \\
$14: 00$ & 33.1 & 34.0 & 0.9 & 97.4 \\
$16: 00$ & 32.7 & 33.6 & 0.9 & 97.3 \\
$18: 00$ & 31.9 & 31.7 & -0.2 & 99.4 \\
$20: 00$ & 28.5 & 28.8 & 0.3 & 99.0 \\
$22: 00$ & 26.4 & 27.2 & 0.9 & 97.1 \\
\hline
\end{tabular}

Table 3. Input-value for simulationof stream restoration.

\begin{tabular}{|c|c|c|c|c|c|c|c|c|}
\hline Index & Model & $\begin{array}{l}\text { Start } \\
\text { Time }\end{array}$ & Duration & $\begin{array}{l}\text { Saving } \\
\text { Interval }\end{array}$ & $\begin{array}{c}\text { Initial } \\
\text { Temperature }\end{array}$ & $\begin{array}{c}\text { Wind } \\
\text { Direction }\end{array}$ & $\begin{array}{l}\text { Wind } \\
\text { Speed }\end{array}$ & $\begin{array}{l}\text { Relative } \\
\text { Humidity }\end{array}$ \\
\hline $\begin{array}{l}\text { Input } \\
\text { Value }\end{array}$ & $\begin{array}{l}\text { Envi-met } \\
\text { (Ver.3.1) }\end{array}$ & PM 10:00 & 24 Hours & 30 Min. & $33.2^{\circ} \mathrm{C}$ & $\begin{array}{l}\text { South } \\
\left(180^{\circ}\right)\end{array}$ & $2.2 \mathrm{~m} / \mathrm{s}$ & $72.9 \%$ \\
\hline
\end{tabular}

energy radiates the highest amount on the ground surface at that time. According to the area of artificial covering, the degree of radiation heat varies. In other words, the radiation heat influence at point 1 , which has the largest artificial covering area, consecutively affected point 2, point 3 and point 4 .

The influence of the radiation heat according to the artificial covering can be found if we have a look at the temperature comparison results before and after the river restoration; there is a significant difference. The temperature difference before and after the river restoration at $2 \mathrm{p} . \mathrm{m}$. at point 1 is $1.33^{\circ} \mathrm{C}$, which is the greatest difference among all other points and times. This is due to temperature reducing effect caused by the difference between the artificial covering material-asphalt and the natural covering material-water that was created by the river restoration. This demonstrates natural covering is a very important factor in creating a temperature reduc- 




Figure 7. Conception of modeling for stream restoration simulation (Left: Before, Right: After).

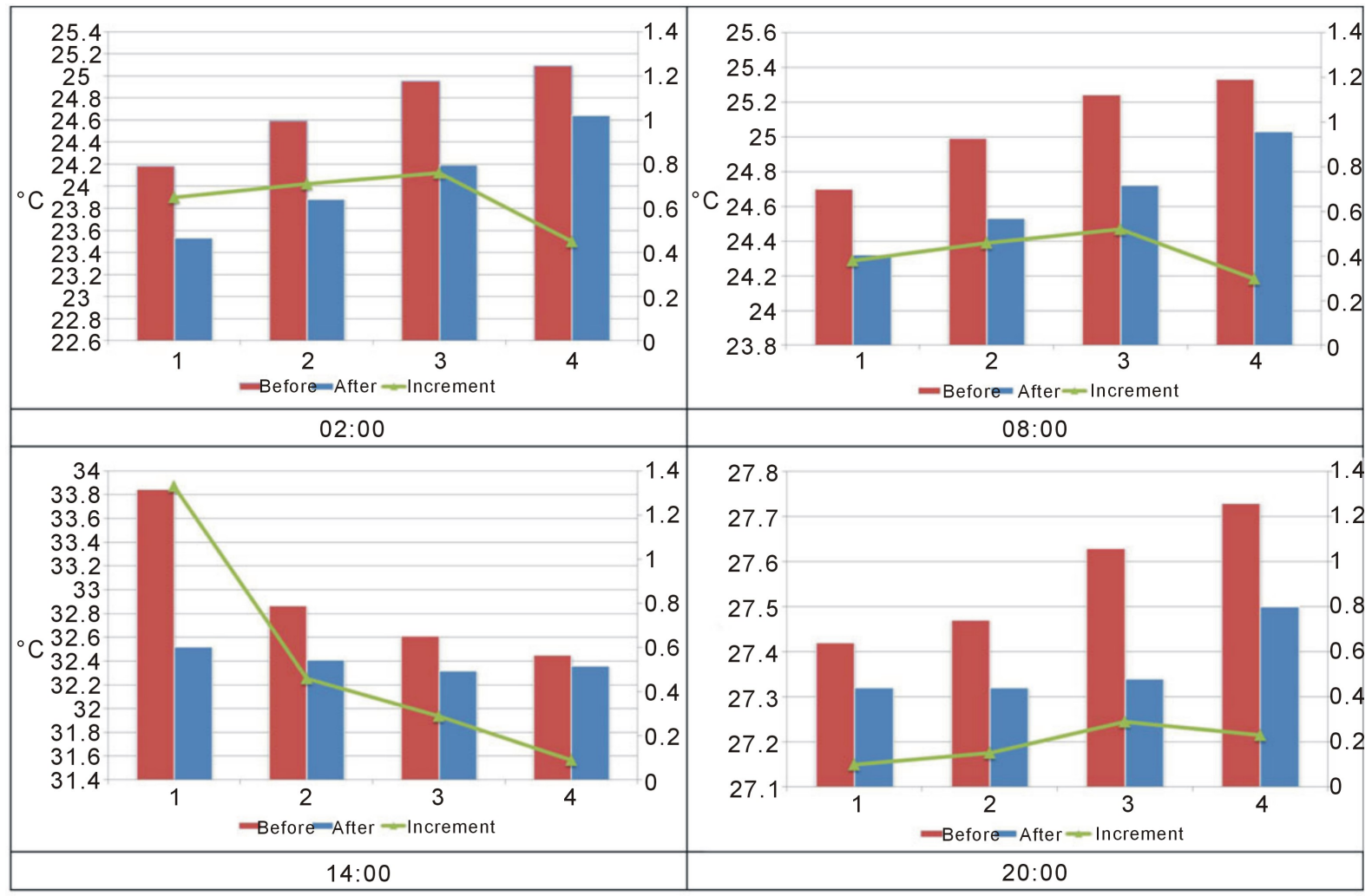

Figure 8. Comparison each point temperature for specific times according to stream restoration.

ing effect in an urban area.

And comparing the temperature before and after the river restoration at 2 a.m. and 8 p.m. when there is not much solar radiation energy and at 8 a.m. when there is a certain amount of solar radiation, the temperature difference increases slowly at point 1 , point 2 and point 3 , and decreases at point 4 . This suggests that the temperature reducing effect that comes with the river restoration can even influence the temperature at point 3 , which is $60 \mathrm{~m}$ from the river. (Refer to Figure 8 ). The temperature comparison of each point before and after the river 
restoration is shown in Table 4.

Figure 9 is a graph that shows the temperature increase/decrease amount of each points before and after the river restoration in the target area. What we can see from this is that the temperature increase/decrease amount shows a significant difference during the day compared to the night time, because of the river restoration. In particular, the temperature difference at point 1 is the greatest from 9 o'clock when solar radiation energy radiates strongly from sunrise to 7 p.m. right before sunset.

This is caused by the difference in specific heat between the natural coverings and the artificial coverings as mentioned above. Once more, it proves that the natural covering materials are very effective in reducing temperature during the day time. In more detail, the highest temperature increase/decrease amount during 24 hours occurred at point 1 , with $-0.71^{\circ} \mathrm{C}$. The lowest temperature increase/decrease amount occurred at point 4 , with an average of $-0.27^{\circ} \mathrm{C}$. And if we arrange the points in order of the highest amount of average increase/decrease, it will be point $1>$ point $2>$ point $3>$ point 4 . We can see that the effect weakens as we move further from the river, when the river is restored.

When looking at temperature increase/decrease amount based on point 1 , the temperature increase/decrease amount at point 4 is comparatively lower than points 2 and 3. Therefore, we can say the influence of the temperature reducing effect that comes with the river restoration is beneficial up to the point 3 .

And if we look at the temperature increase/decrease amount between day and night with the river restoration based on point 1 -the restoration point, the temperature increase/decrease amount during the day time is $-0.93^{\circ} \mathrm{C}$ whereas it is $-0.48^{\circ} \mathrm{C}$ during the night. Therefore the temperature reducing effect is approximately $94 \%$ greater during the day than the night. This shows once again that the natural covering materials are more effective in reducing temperature during the day time than the night time as mentioned above.

The comparison results of temperature increase/decrease amount during the day/night time with the river restoration are shown in Table 5.

Table 4. Comparison each point temperature for specific times according to stream restoration (Unit: ${ }^{\circ} \mathrm{C}$ ).

\begin{tabular}{|c|c|c|c|c|c|c|c|c|c|c|c|c|}
\hline \multirow{2}{*}{ Time } & \multicolumn{3}{|c|}{ Point 1} & \multicolumn{4}{|c|}{ Point 2} & \multicolumn{2}{|c|}{ Point 3} & \multicolumn{3}{|c|}{ Point 4} \\
\hline & Before & After & Increment & Before & After & Increment & Before & After & Increment & Before & After & Increment \\
\hline 02:00 & 24.18 & 23.53 & -0.65 & 24.59 & 23.88 & -0.71 & 24.95 & 24.19 & -0.76 & 25.09 & 24.64 & -0.45 \\
\hline 08:00 & 24.70 & 24.32 & -0.38 & 24.99 & 24.53 & -0.46 & 25.24 & 24.72 & -0.52 & 25.33 & 25.03 & -0.30 \\
\hline $14: 00$ & 33.85 & 32.52 & -1.33 & 32.87 & 32.41 & -0.46 & 32.61 & 32.32 & -0.29 & 32.45 & 32.36 & -0.09 \\
\hline 20:00 & 27.42 & 27.32 & -0.10 & 27.47 & 27.32 & -0.15 & 27.63 & 27.34 & -0.29 & 27.73 & 27.50 & -0.23 \\
\hline Average & 27.54 & 26.92 & -0.62 & 27.48 & 27.04 & -0.44 & 27.61 & 27.14 & -0.47 & 27.65 & 27.38 & -0.27 \\
\hline
\end{tabular}



Figure 9. Comparison increase/decrease amount of temperature for each point according ti stream restoration. 
Table 5. Comparison increase/decrease amount of temperature for each point according to stream restoration (Unit: $\left.{ }^{\circ} \mathrm{C}\right)$.

\begin{tabular}{cccccccccc}
\hline \multirow{2}{*}{$\begin{array}{c}\text { Time } \\
\text { (Day/Night) }\end{array}$} & \multicolumn{2}{c}{ Point 1 } & \multicolumn{2}{c}{ Point 2 } & \multicolumn{2}{c}{ Point 3 } & \multicolumn{2}{c}{ Point 4} \\
\cline { 2 - 9 } 07:00/19:00 & Day & Night & Day & Night & Day & Night & Day & Night \\
08:00/20:00 & -0.62 & -0.31 & -0.70 & -0.03 & -0.76 & -0.12 & -0.46 & -0.14 \\
09:00/21:00 & -0.38 & -0.10 & -0.46 & -0.15 & -0.52 & -0.29 & -0.30 & -0.23 \\
10:00/22:00 & -0.84 & -0.12 & -0.51 & -0.32 & -0.41 & -0.44 & -0.30 & -0.32 \\
11:00/23:00 & -1.10 & -0.71 & -0.56 & -0.75 & -0.41 & -0.79 & -0.24 & -0.46 \\
12:00/24:00 & -1.26 & -0.68 & -0.54 & -0.72 & -0.36 & -0.77 & -0.17 & -0.45 \\
13:00/01:00 & -1.31 & -0.66 & -0.49 & -0.71 & -0.31 & -0.76 & -0.13 & -0.45 \\
14:00/02:00 & -1.33 & -0.65 & -0.46 & -0.71 & -0.29 & -0.76 & -0.09 & -0.45 \\
15:00/03:00 & -1.28 & -0.63 & -0.41 & -0.71 & -0.26 & -0.75 & -0.07 & -0.45 \\
16:00/04:00 & -1.19 & -0.63 & -0.37 & -0.71 & -0.21 & -0.75 & -0.04 & -0.45 \\
17:00/05:00 & -1.01 & -0.63 & -0.41 & -0.70 & -0.26 & -0.75 & -0.05 & -0.46 \\
18:00/06:00 & -0.67 & -0.62 & -0.33 & -0.70 & -0.18 & -0.75 & 0.00 & -0.45 \\
Average & -0.93 & -0.48 & -0.44 & -0.54 & -0.34 & -0.61 & -0.16 & -0.38 \\
Total Average & & -0.71 & -0.49 & & -0.47 & & -0.27 &
\end{tabular}

3) Summary of the thermal environment analysis with the river restoration

To summarize the thermal environment analysis carried out on the covered area in the target area beforeand after the river restoration, the results are as follows.

First of all, if we look at the temperature comparison result by time in the whole target area, at $2 \mathrm{p} . \mathrm{m}$. the temperature drops by an average of $0.31^{\circ} \mathrm{C}$ when the river is restored. This was the highest temperature reduction, approximately $0.95 \%$ for the whole target area. However, the temperature increase/decrease amount at 2 a.m. is $-0.01^{\circ} \mathrm{C}$, which is the lowest temperature reduction. If we look at the temperature comparison results during the day/night in the whole target area, the average temperature increase/decrease amount during the day time (7 a.m. -6 p.m.) is $-0.18^{\circ} \mathrm{C}$, whereas the average was $-0.02^{\circ} \mathrm{C}$ during the night time $(7$ p.m. -6 a.m.). This shows that the temperature decrease amount during the day time is greater by approximately $0.16^{\circ} \mathrm{C}$ compared to the night time.

If we look at the temperature comparison results of each major point in the target area at 2 a.m., 8 a.m. and 8 p.m., but omitting 2 p.m., the temperature difference gets bigger as we move from point 1 to point 4 . However at $2 \mathrm{p} . \mathrm{m}$. the temperature difference gets smaller as we move from point 1 to point 4 . In particular, the temperature difference at point 4 at $2 \mathrm{p} . \mathrm{m}$. before and after the river restoration is $1.33^{\circ} \mathrm{C}$, which is the biggest difference among all the times and points. This is because point 1 has the biggest difference in terms of artificial covering area and natural covering area; therefore the radiation heat difference is the biggest at that point. In other words, the biggest temperature difference is at point 1 where the area coverings changed to natural coverings after the river restoration, and such a temperature difference caused by radiation heat affected points 2, 3 and 4 in a successive manner.

Also, if we look at the temperature comparison results between day/night at the major points of the target area, the average temperature increase/decrease amount during the night time at point 1 , the river restoration point, is $-0.48^{\circ} \mathrm{C}$ and $-0.93^{\circ} \mathrm{C}$ during the day time. Therefore, the temperature reducing effect during the day time is $94 \%$ greater than during the night time. This tells us that natural covering materials are more effective in temperature reduction during the day time than night time.

Finally, we looked at the influence of the river restoration on the residential areas around the river on the basis of temperature comparisons before and after the river restoration between 2 a.m. and 8 a.m. when there is no solar radiation energy, and 8 a.m. when a certain amount of solar radiation started to take effect, and we found that the temperature difference increased slowly at points 1,2 and point 3 , and then decreased from point 4 . This suggests the possibility that the temperature reducing effect that comes with the river restoration could span up to $60 \mathrm{~m}$ around the river.

\section{Conclusions}

The conclusion derived from this result is that rivers have quite an influence over the thermal environment in the 
urban areas. Accordingly, in order to improve comfort living conditions in a city and promote a temperature reducing effect during the day time, natural coverings should be utilized more than the artificial coverings as much as possible.

Of course, we appreciate that the research would benefit by selecting more target areas for onsite measurements, secure greater objectivity and reliability with regard to results by considering various directions of the wind, and furthermore, the accuracy of the research should be improved by modeling verification in order to improve the quality of the research. However, the development of an analysis model that reflects the urban environments in our country is prerequisite to improving this kind of research. With such prerequisites established, we believe objectivity and reliability can be secured through continuous research in the future.

Finally, we regard this research to be meaningful in that it analyzes quantitatively the influence of river restoration on the thermal environment of residential areas around the river, and if these results are reflected in river restoration plans in the future, it will be helpful in creating more comfortable and healthier green urban landscapes.

\section{Acknowledgements}

This work was supported by the environmental technology development project grant funded by the Daegu Green Environment Center (DEGEC) in 2011 (No. 11-1-80-81-01).

\section{References}

[1] Gim, Y.H. (2009) A Study on the River Improvement Method for the Ecological Restoration of Urban Streams. Master's thesis, University of Ulsan Graduate School, Ulsan.

[2] Han, S.G. (2007) The Effect of the Restored Choenggye Stream on Heat Island Intensity and Building Cooling Load in the Surrounding Area. Master's Thesis, University of Seoul Architectural Engineering, Seoul.

[3] Kim, C.H. (2005) A Study on the Nature-Friendly Streamlining for Ecological Restoration. Master's Thesis, Dankook University Graduate School of Industrial Management, Seoul.

[4] Bruse, M. (2007) Simulation Human Thermal Comfort and Resulting Usage Patterns of Urban Open Spaces with a Multi Agent System. Proceedings of the 24th International Conference on Passive and Low Energy Architecture PLEA, Singapore City, 22-24 November 2007, 699-706.

[5] Ali-Toudert, F. and Mayer, H. (2007) Effects of Asymmetry, Galleries, Overhanging Facades and Vegetation on Thermal Comfort in Urban Street Canyons. Solar Energy, 81, 742-754. http://dx.doi.org/10.1016/j.solener.2006.10.007

[6] Yu, C. and Hien, W.N. (2006) Thermal Benefits of City Parks. Energy and Buildings, 38, 105-120. http://dx.doi.org/10.1016/j.enbuild.2005.04.003

[7] Kim, S.B., Ryu, Y.S., Moon, H.S. and Sim, J.H. (2007) Understanding of the City Parks and Recreation. Munundang, Korea.

[8] Kwon, T.H., Kim, K.R., Byon, J.Y. and Choi, Y.J. (2009) Spatiotemporal Changes of the Thermal Environment by the Restoration of an Inner-City Stream. Environment Impact Assessment Article, 18, 320-330.

[9] Woo, H.S. (2009) What Is the River Restoration? Korea Institute of Construction Technology, Korea, 6-12.

[10] Ministry of Environment in Korea \& Korea Environment Corporation (2011) Ecological River Restoration Guidebook. Korea.

[11] Ministry of Environment in Korea \& Korea Environment Corporation (2011) Technical Manual for Ecological River Restoration. Korea.

[12] Ministry of Land, Transport and Maritime Affairs in Korea \& Korea Institute of Construction Technology (2009) Integrated Manual Written for the Existing River Restoration Kit Manual Review. Korea.

[13] Do, W.G., Cho, J.G. and Yoo, P.J. (2010). According to the City Center River Restoration Study: The Effects of Temperature Decrease. Public Health and Environment Research Institute, Korea, 168-177.

[14] Kim, J.K. (2009) An Analysis of Micro-Climate Environmental Changes Followed by Establishment of an Urban Park: In the Case of Daegu. Master’s Thesis, Keimyung University Graduate School, Daegu. 